\title{
Neues Leben mit dem Stoma
}

\author{
Patientenbericht _ Der Amerikaner Bob Baker litt an Colitus ulcerosa. 27 Jahre nach dieser \\ Diagnose ließ er sich ein Stoma legen. Jetzt kann er sein Leben genießen. Und bei einer Wohl- \\ tätigkeitsveranstaltung legte er in nur drei Tagen 350 Kilometer mit dem Rennrad zurück.
}

(1) Seit ich 15 Jahre alt war, beherrschte Colitis ulcerosa mein Leben und hielt mich in permanenter „Alarmbereitschaft“: Ich konnte überall und jederzeit plötzlich Durchfall haben.

Leider viel zu spät, nämlich 27 Jahre nach dieser Diagnose, wurde ich von der Krankheit geheilt: Mein Dickdarm wurde entfernt und die Ärzte legten mir ein Stoma an. Seitdem bin nicht mehr ständig angespannt.

Gesunde Menschen können sich nicht vorstellen, wie es ist, wenn die Angst vor plötzlichem Durchfall zum ständigen Begleiter wird. Ich weiß das leider nur zu gut, denn ich habe fast 30 Jahre an Colitis ulcerosa gelitten. Und das bedeutete für mich: Ganz gleich, ob vor einem beruflichen oder privaten Termin - bevor ich das Haus verließ, habe ich stets recherchiert, wo sich an dem Ort, an dem ich mich einfinden sollte, ein WC befand. Einladungen, bei denen ich diese Frage nicht klären konnte, nahm ich grundsätz- lich nicht an. Außerdem nahm ich immer eine zweite Garnitur mit und legte mir vor jedem Termin eine gute Ausrede zurecht, um mich „notfalls“ schnell zurückziehen zu können. Ich entwickelte mich zu einem Flucht-Spezialisten.

\section{Zwei Jahre „verschenkt“}

Vor fünf Jahren stellten die Ärzte dann bei mir Dickdarmkrebs fest. Bevor sie den Tumor entfernten, rieten sie mir, den Dickdarm gleich mit herausnehmen zu lassen, um mich von der Colitis ulcerosa zu heilen. Weil ich dann aber mit einem künstlichen Ausgang hätte leben müssen, lehnte ich ab. Damals kam für mich ein Stoma einfach nicht in Frage - obwohl ich gar nicht wusste, was das eigentlich für meinen Alltag bedeutet.

Zwei Jahre nach der Darmkrebsoperation wurden die Symptome der Colitis ulcerosa so heftig, dass ich keinen anderen Ausweg mehr sah, als den Darm doch entfernen zu lassen. Diese Entscheidung war eine der besten, die ich in meinem Leben getroffen habe - obwohl ich seitdem mit einem Stoma leben muss. Und natürlich war der Umgang damit zuerst alles andere als einfach.

\section{Neues Lebensgefühl}

Mein Stoma hat mir eine neue Perspektive gegeben. Ich habe Mut geschöpft, bin aktiver geworden und setze mich inzwischen für andere Betroffene ein. Meine Mitmenschen zu unterstützen, hat mir sehr dabei geholfen, mit meiner eigenen Situation zurecht zu kommen. Heute bin ich Mitglied in der amerikanischen United Ostomy Association und Präsident einer lokalen Selbsthilfegruppe für Stomaträger. Ganz wichtig für mich: Ich kann endlich Dinge tun, die früher niemals möglich gewesen wären. Als ich noch unter Colitis ulcerosa litt, habe ich mit meiner Familie nicht einen einzigen Tag entspannt in der Natur verbracht.

- Bob Baker

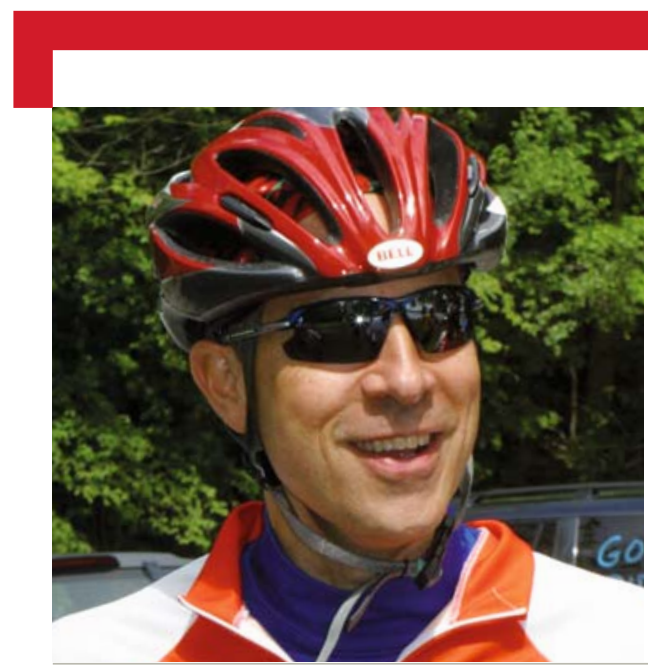

\section{"Seine“ Stomaversorgung finden}

Für alle Patienten, denen erstmals ein Stoma gelegt wird, ist neben der psychosozialen Betreuung eine gute Beratung rund um das Thema Pflegeprodukte sehr wichtig. Weil nicht jede Versorgung für jedes Stoma passt, hilft es Patienten, wenn sie über die große Produktvielfalt gut informiert werden. Sie sollten wissen, dass, wenn die erste Versorgung nicht richtig passt, es immer eine Alternative gibt. Bob Baker: „Durch Ausprobieren kann jeder "sein“ Produkt finden. Ich spreche das deshalb an, weil man mir diesen Tipp nicht gegeben hat. Mit den Produkten, die mir die Pflegekräfte empfohlen hatten, kam ich leider nicht zurecht. Sie saßen nicht richtig, so dass meine Haut immer wieder mit den Ausscheidungen in Kontakt kam, wund wurde und schmerzte. Ich schrieb daraufhin alle Hersteller von Versorgungen für Stomaträger an und bat sie um Zusendung von Mustern. Nach Monaten des Ausprobierens fand ich schließlich „meine“ Versorgung: den modellierbaren Hautschutz. Für mich eine große Erleichterung!" 